\title{
Age related muscle texture variation between Cobb-500 and Ross broiler strain
}

\author{
M. T. Rahaman ${ }^{1}$, M. S. Rahman ${ }^{1}$, M. F. Hoque ${ }^{2}$ and N. H. Parvez ${ }^{1}$ \\ ${ }^{1}$ Department of Anatomy and Histology, ${ }^{2}$ Department of Medicine, Surgery and Obstetrics, Hajee Mohammad \\ Danesh Science and Technology University, Dinajpur-5200, Bangladesh
}

\begin{abstract}
Meat characteristics of Cobb-500 and Ross boiler strains in terms of histomorphometry of myocyte, fat tissue and connective tissue were studied. Two representative muscles from breast (Pectoralis thoracis and Supracoracoideus) and two from thigh (Ilitibialis lateralis and Iliotibialis cranialis) were selected. Thicker myofiber in breast and thinner myofiber in thigh were found in Ross strain. The perimysial thickness significantly differed among the muscles. The perimysial thickness of breast and thigh muscle at $28^{\text {th }}$ day and thigh muscle at $35^{\text {th }}$ day of Cob-500 were found higher that indicate more toughness of representative muscles. Thick and broad bundles of collagen fiber were observed in perimysium of llitibialis lateralis and thinner but broad bundles were in perimysium of Pectoralis thoracis muscle. At $35^{\text {th }}$ day of age the endomysial thickness was found same in both strains but at $28^{\text {th }}$ day of age it was higher in Cobb-500 than that of Ross strain. The intramuscular fat deposited mainly within perimysium as cluster and the number (per focus) and the size of adipocyte diameter was differed among the muscles. Adipocytes diameter was recorded highest $(24.14 \pm 1.33 \mu)$ in pectoralis thoracis muscle of Ross boiler and $22.01 \pm 1.74 \mu$ second in position in Cobb-500. The lowest diameter $15.62 \pm 0.87 \mu$ ) was recorded in case of iliotibialis lataralis muscle of Ross boiler.
\end{abstract}

Keywords: Age, Strain, Meat characteristics, Broiler

\section{Introduction}

There is lack of sufficient animal protein in developing countries like Bangladesh due to population explosion. Poor people can hardly manage the standard daily requirment of protein. To fulfill this shortage commercial boiler can play an important role. Still boiler is the cheapest meat source in Bangladesh and it contributes $30 \%$ to the total animal protein for human consumption (Huque, 1996). Small scale commercial boiler farms are gradually rising due to their production yield in shortest period of time and low investment. Different strains of commercial boiler are reared in Bangladesh. Texture is the most important factor in determining meat quality of boiler from consumer's point of view (Dransfield et al. 1999). Meat texture depends on structures and composition of skeletal muscle, which is mainly, consists of muscle fibers and surrounding intramuscular connective tissue and fat deposition (Nishimura, 1999). But no sufficient research took place till now in Bangladesh regarding comparative study of meat characteristics among different boiler strain. So, the present research has been carried out to investigate age related muscle texture variation between Cobb-500 and Ross broiler strain.

\section{Materials and Methods}

A total 288 boilers, meaning 144 Cobb-500 and 144 Ross from 16 small scale farms were taken as biological sample. All the birds were fed with locally available feed (Kazi feed). The birds were slaughtered manually with the help of sharp knife, through ventral neck cutting. Following skinning \& removal of subcutaneous fat, two representative muscles of breast (Pectoralis thoracis and Supracoracoideus) and two from thigh (Ilitibialis lateralis and Iliotibialis cranialis) were selected. About 1 $\mathrm{cm}$ of each muscle (3 $\mathrm{mm}$ in thickness) was preserved in $10 \%$ formalin for histological study. Same procedure was followed at $28^{\text {th }}$ and $35^{\text {th }}$ day of age. The tissue samples were dehydrated in ascending grade of alcohol, cleared in xylene, Infiltrated and finally embedded in Paraffin. The sections are cut at $6 \mu$ thickness and stained with hematoxyline and eosin ( $H$ \& E) stain for general histological study. Perimysial and endomysial thickness, thickness of individual muscle fiber and adipocyte diameter were measured in 5 random microscopic focuses in each slide with the help of calibrated ocular micrometer. One small unit of calibrated ocular micrometer had the value of $14.5 \mu$ when the tissues were observed under 10 objectives and 8 eyepiece. The raw data were recorded, entered and sorted using the MS excel. The data were calculated by one sample t-test and then transferred to analytical software SPSS (Version 11.5) for analysis. Initially the data were stored and cross cheeked for duplication and /or missing value. The missing values for each variable were recorded (numeric) as to be excluded in the analysis. 


\section{Result and Discussion}

\section{Structure of Muscle bundle}

Group of muscle fibers surrounded by connective tissue layer, perimysium forming muscle fascicles was studied. Within the muscle fascicles the myocyte thickness was measured (Table 2). At 35 days of age the myocyte of pectoralis thoracis of Ross strain was thicker $(26.98 \pm 1.42 \mu)$ than that of Cobb-500 strain $(25.56 \pm 1.74 \mu)$ and this result was in agreement with Radu-Rusu et al., (2008) but in thigh region, myocyte of iliotibialis lateralis muscle of Cobb-500 was thicker $(24.14 \pm 1.74 \mu)$ than that of Ross broiler $(23.43 \pm 1.42 \mu)$. At 28 days of age the muscle fiber of pectoralis thoracis of Ross broiler was thicker $(24.85 \pm 1.59 \mu)$ than that of Cobb-500 $(24.14 \pm 1.74 \mu)$ and in iliotibialis lateralis of Ross broiler was thinner $(22.01 \pm 0.71 \mu)$ in comparison to that of Cobb-500 broiler strain $(22.72 \pm 0.87 \mu)$ (Table 2) and this result was in agreement with Radu-Rusu et al., (2008).

The individual muscle fibers were surrounded by a layer of delicate collagen and reticular fibers called endomysium (Plate 3). The endomysial thickness and interfiber gap was varied from muscle to muscle (Table 1). In the present study the individual muscle fiber of iliotobialis lateralis of the thigh at $28^{\text {th }}$ day of age was more compact than the pectoralis thoracis of the breast muscles. At $35^{\text {th }}$ day of age the endomyseal thickness was found same in both strains but at the day of 28 it was higher in Cobb-500 than that of Ross strain.

Table 1. Perimyseal and Endomyseal thickness (Mean \pm SEM) of two selected muscles at $28^{\text {th }}$ and $35^{\text {th }}$ days old of Cobb-500 and Ross broiler strains $(n=5)$

\begin{tabular}{|l|c|c|c|c|}
\hline \multirow{2}{*}{ Parameters } & \multicolumn{2}{|c|}{ Cobb-500 } & \multicolumn{2}{c|}{ Ross } \\
\cline { 2 - 5 } & $\begin{array}{c}\text { Perimyseal } \\
\text { thickness }(\mu)\end{array}$ & $\begin{array}{c}\text { Endomyseal } \\
\text { thickness }(\mu)\end{array}$ & $\begin{array}{c}\text { Perimyseal } \\
\text { thickness }(\mu)\end{array}$ & $\begin{array}{c}\text { Endomyseal } \\
\text { thickness }(\mu)\end{array}$ \\
\hline Day-28 & $63.90 \pm 3.18$ & $9.94 \pm 1.33$ & $62.48 \pm 2.66$ & $9.23 \pm 1.42$ \\
\hline Pectoralis thoracis & $62.48 \pm 3.48$ & $9.23 \pm 1.42$ & $61.06 \pm 2.84$ & $8.52 \pm 0.87$ \\
\hline Iliotibialis lateralis & \multicolumn{4}{|l|}{} \\
\hline Day-35 & $76.68 \pm 7.24$ & $11.36 \pm 1.74$ & $79.52 \pm 7.24$ & $11.36 \pm 1.74$ \\
\hline Pectoralis thoracis & $65.32 \pm 3.49$ & $11.36 \pm 1.33$ & $62.48 \pm 3.48$ & $11.36 \pm 1.33$ \\
\hline Iliotibialis lateralis
\end{tabular}

Mean \pm SE within a raw are statistically significant $(P<0.01)$

$\mathrm{SE}=$ Standard error

Table 2. Adipocyte and Myocyte thickness (Mean \pm SEM) of two selected muscles of $28^{\text {th }}$ and $35^{\text {th }}$ days old of Cobb-500 and Ross broiler strains $(n=5)$

\begin{tabular}{|l|c|c|c|c|}
\hline \multirow{2}{*}{ Parameters } & \multicolumn{2}{|c|}{ Cobb-500 } & \multicolumn{2}{c|}{ Ross } \\
\cline { 2 - 5 } & $\begin{array}{c}\text { Myocyte } \\
\text { thickness }(\mu)\end{array}$ & $\begin{array}{c}\text { Adipocyte } \\
\text { thickness }(\mu)\end{array}$ & $\begin{array}{c}\text { Myocyte } \\
\text { thickness }(\mu)\end{array}$ & $\begin{array}{c}\text { Adipocyte } \\
\text { thickness }(\mu)\end{array}$ \\
\hline Day-28 & $24.14 \pm 1.74$ & $19.88 \pm 1.42$ & $24.85 \pm 1.59$ & $19.17 \pm 0.87$ \\
\hline Pectoralis thoracis & $22.72 \pm 0.87$ & $17.04 \pm 1.33$ & $22.01 \pm 0.71$ & $15.62 \pm 0.87$ \\
\hline Iliotibialis lateralis & \multicolumn{5}{|l|}{} \\
\hline Day-35 & $25.56 \pm 1.74$ & $22.01 \pm 1.74$ & $26.98 \pm 1.42$ & $24.14 \pm 1.33$ \\
\hline Pectoralis thoracis & $24.14 \pm 1.74$ & $19.17 \pm 1.42$ & $23.43 \pm 1.42$ & $19.88 \pm 1.42$ \\
\hline lliotibialis lateralis
\end{tabular}

Mean \pm SE within a raw are statistically significant $(P<0.01)$

$\mathrm{SE}=$ Standard error 


\section{Connective tissue content}

Entire muscle was surrounded by dense connective tissue called epimysium. The muscle bundle were surrounded by loose connective tissue chiefly consists of bundles of collagen fibers called perimysium. In the present study the perimysium thickness was significantly $(P<0.01)$ differed among the muscles between the Cobb-500 and Ross strain (Table 1). Highest perimysial thickness $(79.52 \pm 7.24 \mu$ ) at 35 days of age was observed in case of pectoralis thoracis muscle of Ross strain which was $76.68 \pm 7.24 \mu$ in case of Cobb-500 (Table 1). Among breast muscles the perimysial thickness of pectoralis thoracis of Ross was thicker $(79.52 \pm 7.24 \mu)$ than that of Cobb-500 strain $(76.68 \pm 7.24 \mu)$ of $35^{\text {th }}$ day of age but the perimysial thickness of iliotibialis lateralis of Cobb-500 was higher $(65.32 \pm 3.49 \mu)$ than that of Ross strain $(62.48 \pm 3.48 \mu)($ Table 1). The same perimysial thickness $(62.48 \pm 2.66 \mu)$ was recorded in pectoralis thoracis of Ross and iliotibialis lateralis $(62.48 \pm 3.48 \mu)$ of Cobb-500 strain at $28^{\text {th }}$ days of age. On the other hand more branched perimysium was observed in case of iliotibialis lateralis muscle. This result was in agreement to that of Nakamura et al., (2004) who recorded higher connective tissue content in thigh muscle than that of breast muscle.

The perimysial thickness was directly related with its collagen fiber content. Thick and broad bundles of collagen fiber were observed in the perimysium of iliotibialis lateralis muscle (Plate 1), thinner but broad bundles were in the perimysium of pectoralis thoracis muscle (Plate 2). This result was in agreement with the report of Nakamura et al., 2003. However, the toughness of the muscle is largely depending on the perimysial thickness. So, the iliotibialis lateralis muscles are tougher among the other muscles of the present study because of their thick and broad endomyseal and perimysial collagen fibers. So the present study indicates that perimysial thickness has a close relationship to the meat toughness and toughness increase with the increase of perimysial thickness. This conclusion is in agreement with the result of Fang et al., 1999. They showed that the toughness of various skeletal muscles of pig significantly correlated with the thickness of perimysium and thickness of perimysium is one of the major factors that determine toughness of pork. A similar finding was also reported in case of chicken skeletal muscles by Liu et al., 1996.

\section{Intramuscular fat deposition}

The intramuscular fat was deposited mainly within the perimysium as cluster of adipocytes (Plate 4). The size of adipocytes deposited, varied among the muscles in the present study (Table 2). Adipocytes diameter was recorded highest $(24.14 \pm 1.33 \mu)$ in pectoralis thoracis muscle of Ross broiler and $22.01 \pm 1.74 \mu$ second in position in Cobb-500. The lowest diameter $15.62 \pm 0.87 \mu$ ) was recorded in case of iliotibialis lataralis muscle of Ross broiler.
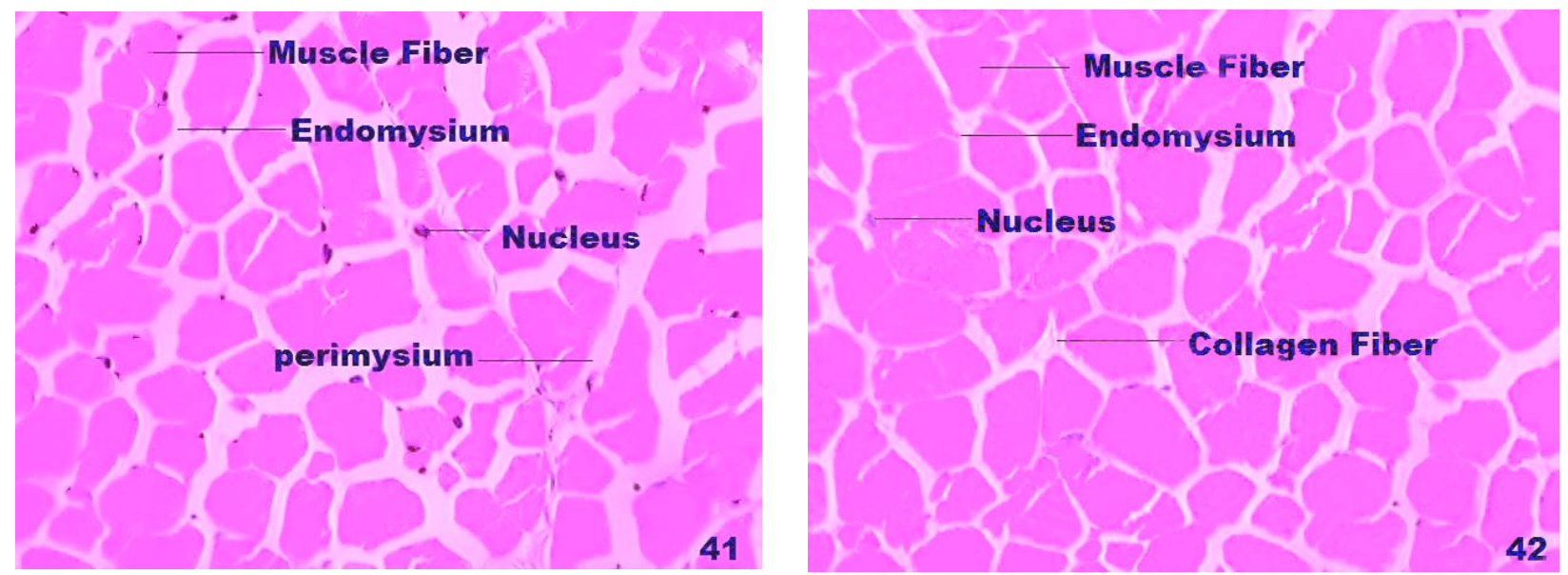

Plate 1. Cross sections of pectoralis trhoracis muscle of Cobb-500 (41) and Ross (42) broiler strains showing perimysium, endomysium, muscle fiber and nucleus at $28^{\text {th }}$ day of age. (H \& E stain, $40 x$ ) 

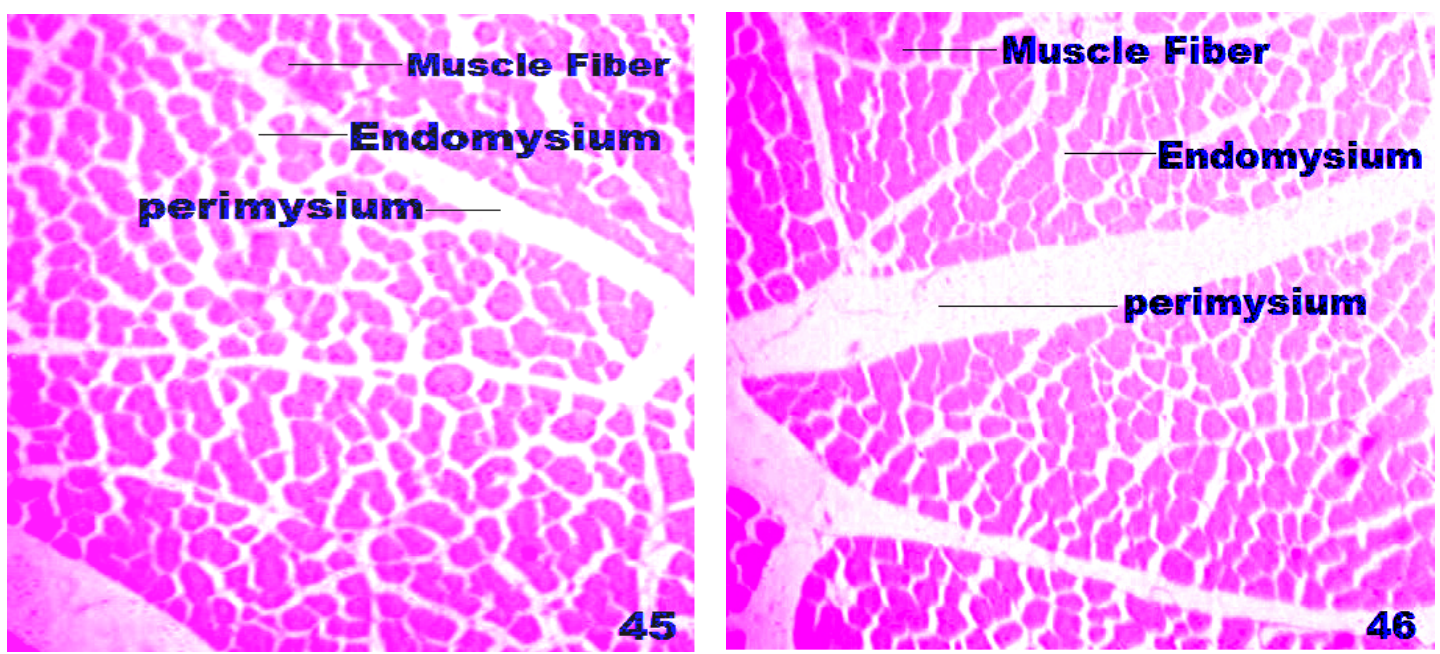

Plate 2. Cross sections of iliotibialis lateralis muscle of Cobb-500 (45) and Ross (46) broiler strains showing perimysium, endomysium and muscle fiber at $28^{\text {th }}$ day of age. ( $H \& E$ stain, $10 x$ )
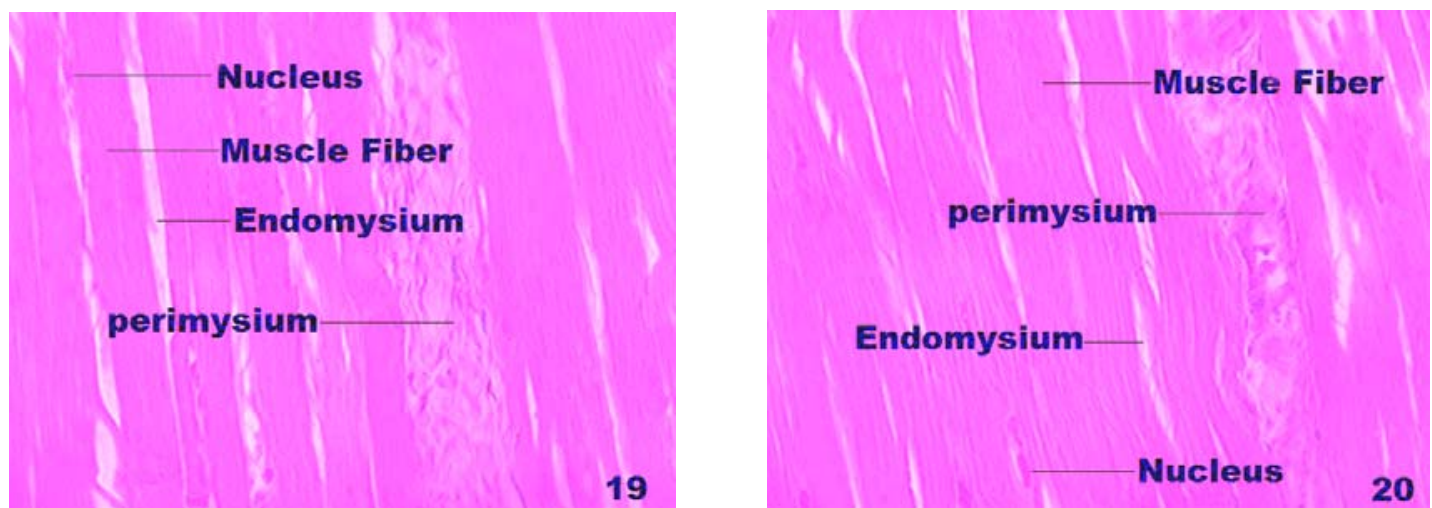

Plate 3. Longitudinal sections of iliotibialis lateralis muscle of Cobb-500 (19) and Ross (20) broiler strains showing endomysium, perimysium, muscle fiber and nucleus at $35^{\text {th }}$ day of age. (H \& E stain, 40x)
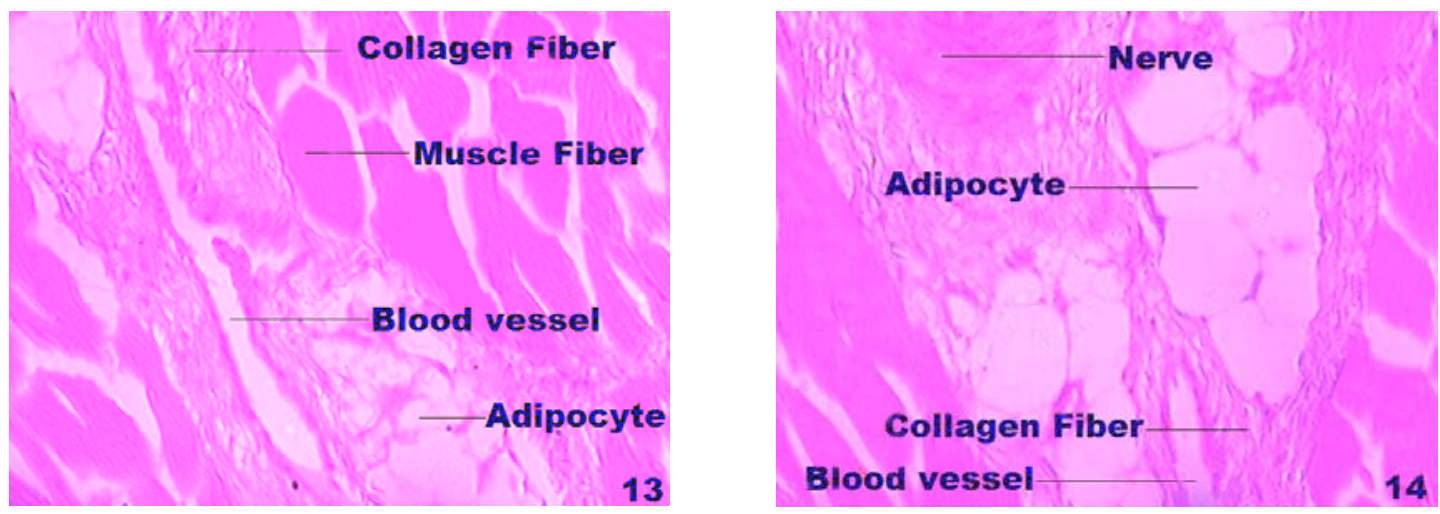

Plate 4. Longitudinal sections of iliotibialis lateralis muscle of Cobb-500 (13) and Ross (14) broiler strains showing collagen fibers, blood vessel, nerve, adipocytes and muscle fiber at $35^{\text {th }}$ day of age. (H \& E stain, 40x) 

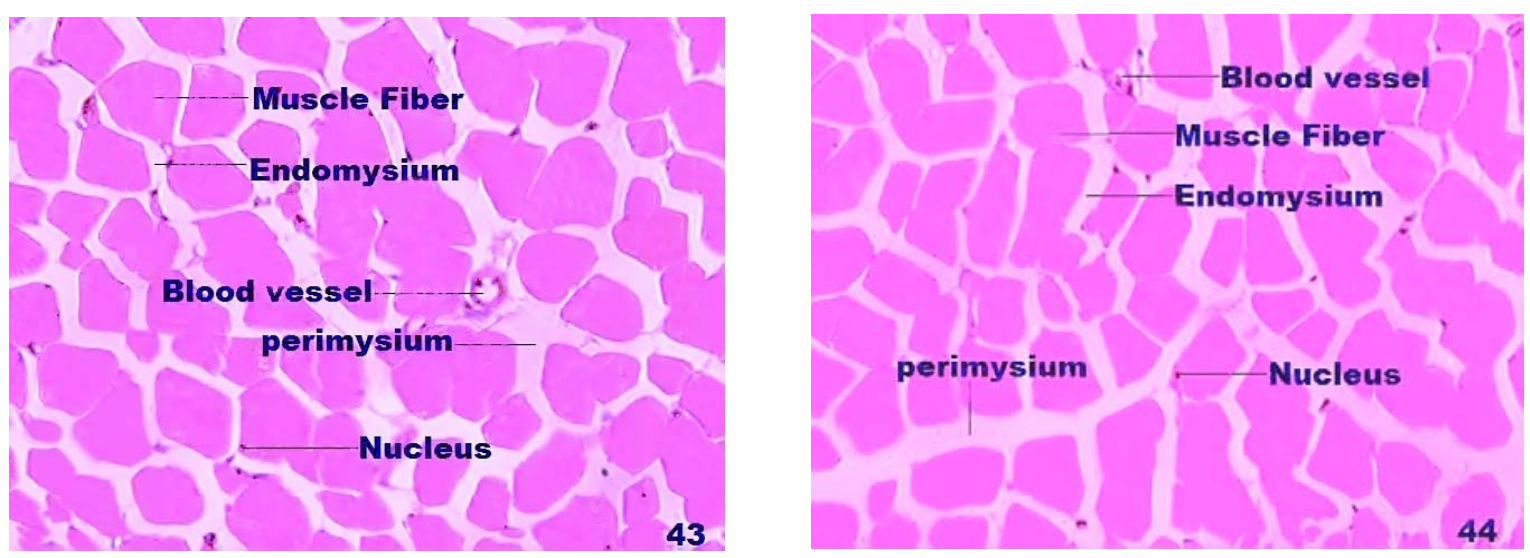

Plate 5. Cross sections of pectoralis trhoracis muscle of Cobb-500 (43) and Ross (44) broiler strains showing perimysium, endomysium, muscle fiber, nucleus and blood vessel at $35^{\text {th }}$ day of age. (H \& E stain, 40x)

In conclusion it can be said that strain selection and age of the bird are two significant criteria in meat industry for improving meat characteristics which distinctly affect the profitability. Ross broiler strain has a better meat characteristics for its lower fat and collagen content in comparision to those of Cobb-500 broiler strain.

\section{References}

Dransfield, E. Sosnicki, A.A. 1999. Relationship between muscle growth and poultry meat quality. Poultry Science, 78(5):743-746.

Fang, S.H., Nishimura, T. and Takahashi, K. 1999. Relationship between development of intramuscular connective tissue and toughness of pork during growth of pigs. Genetic Research, 43:29-34.

Huque, Q.M.E. 1996. Improving Skills of the small farmers in poultry management. Poultry Science, 35:412-418.

Liu, A., Nishimura, T. and Takahashi, K. 1996. Relationship between structural properties of intramuscular connective tissue and toughness of various chicken skeletal muscle. Meat Science. 43:43-49.

Nishimura, T., Hattori, A. and Takahashi, K. 1999. Structural changes in intramuscular connective tissue during the fattening of Japanese Black Cattle. Journal of Animal Science, 77:93-104.

Nakamura, Y.N., Iwamoto, H., Tabata, S., Ono, Y., Shiba, N. and Nishimura, S. 2003. Comparison of collagen content, distribution and architecture among the pectoralis, iliotibialis lateralis and pubioschiofemoralis muscles with different myofiber composition in silky cocks. Animal-Science-Journal. 74(2): 119-128.

Nakamura, Y.N., Iwamoto, H., Shiba, N., Miyachi, H., Tabata, S. and Nishimura, S. 2004. Growth changes of the collagen content and architechture in the pectoralis and iliotibialis lateralis muscles of cockerels. British Poultry Science, 45(6): 753-61.

Radu-Rusu R.M., Teuşan V., Vacaru Opriş I., Usturoi M.G. and Radu-Rusu Cristina. 2008. Histometric assessment of the myocytes within some skeletal muscles issued from COBB-500 commercial broilers, Book of proceedings of the $1^{\text {st }}$ Mediterranean Summit of World Poultry Science Association, Chalkidiki, Greece. p. 1033-1039. 